\title{
A TEORIA DA JUSTIÇA DE RAWLS E AS POLÍTICAS SOCIAIS EM EDUCAÇÃO
}

\section{Marcos Rohling*}

Resumo: Em democracias não tão justas, é preciso políticas públicas sociais para a correção de determinadas injustiças que impedem os cidadãos de ascenderem aos graus adequados do exercício da cidadania. Mais especificamente, é preciso que certas políticas sociais educacionais sejam estabelecidas. Nesse sentido, acredita-se que a teoria da justiça de Rawls seja adequada para avaliar a justiça de tais políticas. Tal intento é realizado, nesse texto, de acordo com a seguinte disposição: em primeiro lugar, são apresentadas as ideias centrais da concepção da justice as fairness, ponto no qual são apresentados os princípios de justiça e a liberdade em $A$ Theory of Justice e mudança em direção a sua determinação como uma concepção política de justiça, destacando as noções de consenso sobreposto (overlaping consensus) e razão pública. Em segundo lugar, apresentar-se-á o sentido em que tal teoria pode avaliar as políticas públicas sociais educacionais, em direção ao qual se apontam a noção de Estado presente na obra de Rawls e o modo como o segundo princípio se relaciona com a educação, de modo a avaliar e a orientar as políticas públicas sociais em educação.

Palavras-chave: Justiça como Equidade. Princípio da Igualdade Equitativa de Oportunidades. Educação. Políticas Sociais em Educação. Rawls.

Resumen: En democracias no tan justas, se necesitan políticas públicas sociales para la corrección de ciertas injusticias que impiden a los ciudadanos ascender a los grados adecuados al ejercicio de la ciudadanía. Más específicamente, es necesario que ciertas políticas sociales en educación sean establecidas. En ese sentido, se cree que la teoría de la justicia de Rawls es adecuada para evaluar la justicia de tales políticas. En este texto, tal intento se realiza de acuerdo con la siguiente disposición: en primer lugar, se presentan las ideas centrales de la concepción de la justice fairness, punto en el que se presentan los principios de justicia y la libertad en $A$ Theory of Justice, así como el cambio en dirección a su determinación como una concepción política de justicia, destacando las nociones de consenso entrecruzado (overlaping consensus) y la razón pública. En segundo lugar, se presentará el sentido en que tal teoría puede evaluar las políticas públicas sociales en educación, em dirección a la cual se apunta la noción de Estado presente en la obra de Rawls y el modo como el segundo princípio se relaciona con la educación para evaluar y orientar las políticas públicas sociales en educación.

Palabras claves: Justicia como Equidad. Princípio de la Igualdad de Equitativa de Oportunidades. Educación. Políticas Sociales en Educación. Rawls.

\footnotetext{
* Professor da Carreira do EBTT do Instituto Federal Catarinense - IFC, Campus Videira. Doutorando em Educação (UFSC), Mestre em Filosofia (UFSC), Graduado em Filosofia, Bacharel e Licenciado (UFSC) $e$ Graduando em Direito (UNOESC). Seus principais interesses são postos na confluência de três áreas: Filosofia, Direito e Educação. Lattes:
}

http://lattes.cnpq.br/1426156565430729. E-mail: marcos_roh@yahoo.com.br. A elaboração desse trabalho contou, à época, com o auxílio do CNPq, mediante bolsa para o doutorado. $\mathrm{O}$ autor agradece, também, à FAPESC pela concessão posterior de bolsa para o seguimento dos estudos doutorais.

ROHLING, Marcos. A teoria da justiça de Rawls e as políticas sociais em educação. Revista SulAmericana de Filosofia e Educação. Número 28: maio-out./2017, p. 27-49. 


\section{Questões Preliminares}

A justiça é um dos grandes problemas da humanidade e de suas instituições. Diz-se a justiça das pessoas, das práticas, das situações e, também, das instituições. Viver em sociedade é, de certo, estar exposto ao movimento de instituições que, dado o contexto democrático, devem ser avaliadas. Trata-se, pois, da avaliação de acordo com os princípios democráticos, os quais exigem certa imparcialidade, tanto quanto benefícios no sentido de favorecer a todos os que são membros dessa determinada sociedade.

A teoria da justiça de Rawls pretende ser uma teoria da justiça distributiva capaz de avaliar a justiça das instituições sociais. A ideia de Rawls é a de que o modo como a sociedade está organizada terá um papel determinante no processo distributivo, já que o futuro pessoal individual está especialmente relacionado ao modo como as instituições são organizadas. Trata-se, é verdade, daquilo que Rawls nomeia como estrutura básica da sociedade, a qual é definida como "o modo como as principais instituições sociais distribuem os direitos e os deveres fundamentais e determinam a divisão das vantagens decorrentes da cooperação social' (RAWLS, 2009, §2, p. 08). No final das contas, a estrutura básica da sociedade é o con- junto de instituições e práticas sociais que sistematicamente influenciam o modo como serão as vidas dos membros de uma determinada sociedade, independentemente do esforço pessoal, e na qual estão inclusos o sistema de governo e as leis, mas, também, a organização da economia e de instituições importantes, como a família, e algumas condições culturais.

Nesse sentido, crê-se que a teoria da justiça de Rawls é perfeitamente adequada para avaliar a justiça das políticas publicas sociais educacionais, já que, em certo sentido, as instituições educacionais, embora não especificamente nomeadas por Rawls, pertencem ao quadro das instituições elementares de uma sociedade. Sendo assim, o texto será dividido em duas partes principais, mas que estão intimamente relacionadas: inicialmente, a apresentação das idéias mais identitárias da concepção da justice as fairness. Nesse ponto, são apresentados os princípios de justiça e a liberdade em $A$ Theory of Justice $^{2}$, assim como a ideia central do giro político feito por Rawls, no qual se desteçam o consenso sobreposto (overlaping consensus)

\footnotetext{
${ }^{2}$ Doravante, utilizar-se-á $T J$ para se referir a $A$ Theory of Justice (Revised Edition), Cambridge: Harvard University Press, 2000 [trad. Bras: Jussara Simões. São Paulo: Martins Fontes, 2009] e PL para Political Liberalism, New York, NY: Columbia University Press, 1993 [trad. Bras.: Dinah de Abreu Azevedo. São Paulo: Ática, 2000].
} 
e a razão pública. Num segundo momento, apresentar-se-á o sentido em que tal teoria pode avaliar as políticas públicas sociais educacionais. Para tanto, aponta-se a noção de Estado presente na obra de Rawls e o modo como o segundo princípio, especialmente em relação à educação, de modo a avaliar e a orientar as políticas públicas sociais em educação.

\section{A Teoria da Justice as Fairness}

A teoria da justice as fairness, a justiça como equidade, sofreu mudanças significativas ao longo dos anos, desde a inicial publicação de artigos, durante as décadas de 50 e 60, passando pela publicação de $A$ Theory of Justice, em 1971, primeira formulação completa da teoria, a grande reformulação de Political Liberalism, em 1993, até chegar à última versão em Justice as Fairness: $A$ Restatement, em 2001. De modo geral, a teoria da justiça de Rawls advoga a escolha de princípios de justiça, por meio da qual os termos da cooperação social são estabelecidos por pessoas livres e iguais comprometidas por um esquema de cooperação, numa posição originária (original position). A posição original é um dispositivo de representação no qual as partes estão condicionadas pelo véu da ignorância, assim como estão dotadas de racionalidade instrumental e são mutuamente desinteressadas. Assim postas, as partes escolhem imparcialmente, independentemente de suas preferências pessoais, do status social e dos indivíduos que representam.

A teoria da justiça como equidade é, desse modo, uma teoria contratualista, ainda que limitadamente contratualista, que se vale do contrato, entre uma lista de alternativas, para a escolha de princípios de justiça, os quais constituirão a base para justificar as instituições públicas, bem como fundamentar os deveres e as obrigações dos cidadãos. $\mathrm{O}$ contratualismo de Rawls é, no entanto, distinto do contratualismo moderno, posto que, como salienta Merquior, a natureza do empreendimento de Rawls de reabilitar o contratualismo, alçando-o à posição de alternativa ao utilitarismo, mostrou-se num plano processual, "pois foi nas técnicas que empregou para deduzir princípios de justiça que Rawls adotou uma posição contratualista" (MERQUIOR, 1990, p. 206). Desse modo, o contrato social que Rawls tem em mente

[...] era um contrato social muito diverso
do contrato social da primeira tradição
moderna, já que seu propósito não con-
sistia no estabelecimento de autoridade
e obrigação legítimas, como em Hobbes,
Locke ou Rousseau, mas em firmar re-
gras de justiça (MERQUIOR, 1990, p.
206).

Ao apresentar a melhor concepção de justiça, o filósofo está preocupado em afas- 
tar, na terminologia de Adam Smith, o sistema de liberdade natural, entendido no sentido de que protegeria apenas as liberdades básicas, retirando da esfera da justiça a construção da igualdade de oportunidades $e$ a distribuição da riqueza, de modo a favorecer as instituições de um Estado protetor das liberdades, mas apenas moldado para assegurar a abertura das carreiras ao mérito $e$, igualmente, a eficiência dos mercados, avaliados em termos paretianos. Além disso, Rawls se posiciona contra o sistema da aristocracia natural, sociedade na qual aqueles que são vistos com talentos melhores, em tese, teriam acesso aos cargos e carreiras mais prestigiados. Contra esses sistemas, os da liberdade natural e aristocracia natural, Rawls advoga aquilo que chama igualdade democrática. Tal sistema, diferentemente dos outros, além da proteção das liberdades, requer instituições que estabeleçam uma igualdade de oportunidades substantiva, distinta da meramente formal, e uma distribuição do rendimento e da riqueza de acordo com aquilo que designa por princípio da diferença (ROSAS, THALER \& GONZÁLEZ, 2012, p. 176-7).

Dessa sorte, os princípios que formam a concepção de justiça, segundo Rawls, são mais adequados para a realização da igualdade democrática. Tratam-se, é verdade, de princípios de justiça que se aplicam, especialmente, mas não exclusivamente, às instituições elementares da estrutura básica da sociedade. Em $T J$, a formulação definitiva reza que:

\section{Primeiro Princípio}

Cada pessoa deve ter um direito igual ao mais abrangente sistema total de liberdades básicas iguais que seja compatível com um sistema similar de liberdade para todos.

\section{Segundo Princípio}

As desigualdades econômicas $e$ sociais devem ser dispostas de modo a que tanto:

(a) se estabeleçam para o máximo benefício possível dos menos favorecidos que seja compatível com as restrições do princípio de poupança justa, como

(b) estejam vinculadas a cargos $e$ posições abertos a todos em condições de igualdade equitativa de oportunidades (RAWLS, 2009, §46, p. 376).

Para corporificar os princípios de justiça, Rawls teoriza uma sequência de quatro estágios, cujo papel, segundo Freeman, é estender o experimento hipotético da posição original, que corresponde ao primeiro estágio, aos três estágios posteriores de deliberação e decisão de aplicação hipotética dos princípios de justiça. Ela é, pois, o quadro para deliberar sobre a aplicação dos princípios de justiça. Desse modo, ela não é o procedimento que é executado e utilizado pelos representantes políticos reais para a constatar se a 
Constituição ou as leis são justas ou legítimas. Uma vez que seja esse o caso, conforme argumenta Freeman,

Num mundo ideal, poderia ser um procedimento que os representantes constitucionais ou legislativos refletem $e$ até mesmo imitem; mas no mundo como o conhecemos isto talvez seja pedir demais de nossos representantes, que normalmente carecem de competências filosóficas. Uma Constituição ou leis podem ser relativamente justas sem que ninguém tente imitar ou mesmo refletir sobre os procedimentos hipotéticos de Rawls. A sequência de quatro estágios é um tipo de investigação hipotética sobre a qual você e eu podemos refletir agora, individual ou conjuntamente, para julgar e avaliar a justiça de constituições, leis e decisões judiciais existentes. É uma maneira de descobrir em que grau são compatíveis nossa Constituição e nossas leis com os princípios da justiça, e fornece uma base para a justificação, a argumentação e a crítica em uma sociedade democrática (FREEMAN, 2007, p. 202-3, tradução minha).

As etapas do processo para a aplicação dos princípios da justiça, numa sequência de quatro estágios, podem ser apresentadas do seguinte modo: primeiro estágio: posição original e escolha dos princípios da justiça; segundo estágio: convenção constituinte $e$ estruturação de uma constituição justa; terceiro estágio: legislatura e elaboração de uma legislatura justa; quarto estágio: aplicação das regras a casos particulares pelo executivo e judiciário. Uma vez desenvolvida a sequência de quatro estágios, que servirá de avaliação acerca das práticas e aplicação dos princípios de justiça, bem como da justiça de uma Constituição e de uma legislatura, dentro da concepção da justiça como equidade, em $T J$ Rawls discute a concepção de liberdade, a qual abarca um grau extenso de liberdade igual compatível para o maior número de pessoas, que ficara, até então, muito abstrata. Assim, Rawls pretende que, através do conceito de liberdade aquilo que são as liberdades básicas.

Com efeito, nesse ponto, em relação às versões posteriores, a teoria da justiça como equidade sofreu mudanças significativas em virtude das críticas elaboradas por Hart, que resultou, inicialmente, numa revisão completa em $T J$, e posteriormente, no artigo $A s \mathrm{Li}$ berdades Básicas e a sua Prioridade, mais tarde retomado em PL. Em breves linhas, as críticas de Hart podem ser assim condensadas: Rawls estabelece uma relação de prioridade do primeiro princípio, o das liberdades básicas iguais, sobre o segundo princípio, o da diferença, no marco da qual, em havendo conflitos no efetivo exercício daquelas liberdades fundamentais, também é preciso estabelecer prioridades. $\mathrm{Na}$ opinião de Hart, o problema coloca-se porque o critério adotado por Rawls não é satisfatório para dar conta de estabelecer a prioridade das liberdades (HART, 1975, p. 230-52). 
No contexto de $T J$, a função primária dos princípios de justiça, que se aplicam inicialmente à estrutura básica da sociedade, é governar a atribuição de direitos e deveres $e$ regular as vantagens econômicas e sociais (RAWLS, 2009, §11, p. 73), governo este que se dá tendo o primeiro princípio como padrão primário para a convenção constitucional, de modo a se determinar as liberdades de cidadania igual, a saber:

[...] a liberdade política (o direito ao voto e a exercer cargo público) e a liberdade de expressão e reunião; a liberdade de consciência e de pensamento; a liberdade individual, que compreende a proteção contra a opressão psicológica, a agressão e a mutilação (integridade da pessoa); o direito à propriedade pessoal $e$ a proteção contra a prisão $e$ detenção arbitrárias, segundo o conceito de Estado de Direito (RAWLS, 2009, §11, p. 74).

Essas liberdades devem ser incorporadas e protegidas pela Constituição, num regime democrático e constitucional, conforme o estado de direito vigente. Até a especificação das liberdades básicas na fase constitucional, as liberdades básicas são altamente abstratas, e serão mais especificamente definidas em termos de liberdades constitucionais, dentro de uma estrutura jurídica inerente à democracia constitucional. Conforme Freeman,

[...] por especificação das liberdades básicas na fase constitucional, Rawls quer dizer que as liberdades são altamente abstratas e que deverão ser mais especificamente definidas em termos de liber- dades constitucionais. Nessa linha, a liberdade de pensamento é especificada em tais liberdades como a liberdade de opinião e de expressão, a liberdade de discussão e investigação, o direito de participar na investigação científica, literária e artística de todos os tipos (FREEMAN, 2007, p. 209-10, tradução minha).

A especificação das liberdades definidas pelos princípios de justiça, na ótica da justiça como equidade, é, desse modo, amparada e protegida, no âmbito de um sistema jurídico, como direitos constitucionais, por meio do estado de direito, que é o resultado da aplicação da justiça formal ao sistema jurídico (ROHLING, 2015).

Para Rawls, uma constituição justa faz respeitar o primeiro princípio de justiça, mediante o princípio da participação (RAWLS, 2009, §36, p. 273-4), o que significa que ela deve conceber o Estado como uma associação de cidadãos em pé de igualdade. Ademais, sendo um caso da justiça procedimental imperfeita - que, mesmo que se tenha um critério independente para produzir o resultado correto, não existe um processo factível que seguramente garanta um resultado justo -, tem dois aspectos, quais sejam (RAWLS, 2009, §14, p. 104-5): i) a constituição deve ser um procedimento justo que satisfaz as exigências da liberdade igual; e, ii) a constituição deve ser estruturada de modo que, dentre todas as ordenações viáveis, ela seja 
a que tem maiores probabilidades de resultar num sistema de legislação justo e eficaz. É imperativo que o princípio da igual participação exige que os cidadãos tenham oportunidade de participarem no processo político daquilo a que se chama democracia constitucional, que pode ser organizada nesse sentido. Para Rawls, a democracia constitucional possui certos elementos que, de um modo geral, a caracterizam, em relação a outras formas políticas, inclusive, democráticas.

À luz disso, é patente que, dentre os principais critérios utilizáveis no julgamento da atuação de um representante e das razões que ele apresenta para justificá-las, encontram-se os princípios de justiça. Uma vez que a constituição é o fundamento da estrutura social, o mais elevado sistema de normas que regula e controla outras instituições, Rawls estatui que todos os cidadãos têm o mesmo acesso ao procedimento político que ela estabelece, pois quando o princípio da participação é efetivamente obedecido, o status comum da cidadania igual fica assegurado (RAWLS, 2009, §36, p. 280-1).

De fato, pode-se dizer que as liberdades que se encerram na liberdade política igual, tal qual Rawls a conceitua, não são apenas um meio: elas, reforçando nos cidadãos o senso de seu próprio valor, amplian- do suas sensibilidades intelectuais e morais, lançam a base de uma noção de dever e de obrigação - no marco do dever natural de justiça e do princípio da equidade -, crucial para que as principais instituições sociais justas, entre as quais o direito, sejam efetivamente estáveis.

\subsection{Pluralismo Razoável}

O construtivismo kantiano define o método que Rawls usa para a elaboração das mudanças em relação à $T J$, no giro político que teve sua teoria. Em PL, Rawls afirma que parte de um conceito de pessoa muito próximo daquele de Kant, conceito este que leva em consideração duas características morais fundamentais, a saber, um senso de justiça e uma concepção de bem. Consideradas como autônomas e reciprocamente livres e iguais, as pessoas constroem os princípios de justiça por meio de um procedimento, pelo qual o resultado deve ser considerado justo, desde que as condições sejam consideradas como tal pelos participantes,

Essa ideia de pessoa é essencial para que se compreenda o entendimento de que as sociedades democráticas são marcadas pelo fato do pluralismo razoável, isto é, as sociedades contemporâneas são marcadas por um pluralismo de concepções abrangen- 
tes do bem - isto é, concepções que representam um conjunto amplo e coerente de valores e princípios, tais como doutrinas filosóficas, morais e religiosas, mediante os quais as pessoas orientam as suas vidas. Trata-se de entender o modo através do qual uma tal sociedade pode ter a finalidade da garantia da justiça e da estabilidade assegurada $e$ implementada e da justificação de questões políticas essenciais que devem sê-lo publicamente. Para isso, Rawls introduz dois elementos: o de consenso sobreposto e o de razão pública. O conceito de consenso sobreposto (overlapping consensus) tem por finalidade manter a estabilidade das instituições democráticas. Isso quer dizer, em outras palavras, que uma sociedade precisa ser regulada por um senso público de justiça, que, conforme se vê em Rawls, ordenas as forças sociais a trabalharem em favor de expectativas comuns, de modo a dar o apoio necessário às instituições básicas para concretizar seus objetivos (OLIVEIRA \& ALVES, 2010, p. 34).

Com efeito, o liberalismo político garante a unidade e a estabilidade da sociedade democrática através do consenso sobreposto, consagrando, desse modo, os direitos $e$ as liberdades básicas em vista da garantia do pluralismo. Trata-se, então, de um modo de consenso por meio do qual as diferentes doutrinas abrangentes, sejam elas filosóficas, morais, políticas ou religiosas, encontram sua unidade ao aprovarem a concepção política de justiça, notadamente, a justiça como equidade. Portanto, a justificação pública entre as várias concepções abrangentes deve compartilhar um núcleo de valores e princípios, que são dados através do overlapping consensus.

Para que esse consenso seja possível, a justificação pública deve se basear sobre o uso da razão pública, isto é, aquela razão que não se assenta sobre as concepções abrangentes do bem. Dessa feita, é preciso que, no interior da sociedade bem ordenada, surjam acordos visando a promoção da justiça e da igualdade, e que desses acordos resultem um consenso político em torno de determinadas questões fundamentais. São essas questões que darão respaldo às instituições de modo a sustentar a estabilidade de uma democracia constitucional. Além disso, esses acordos devem ser formulados em torno dos valores políticos fundamentais, os quais são expressos nos princípios e nos ideais dos membros da sociedade bem ordenada (OLIVEIRA \& ALVES, 2010, p. 34$5)$.

\section{O Estado e sua Função no Pensamento de Rawls}


É necessário esclarecer que Rawls não é um teórico que enfatiza o Estado em sua teoria política, pondo em relevo, inversamente, em primeiro lugar, o papel que os indivíduos têm, nas suas relações com as instituições, as quais devem respeitá-los em seus direitos e deveres correlatos, e, em segundo lugar, a função das próprias instituições na realização da justiça - que inequivocamente são as mesmas que formam um Estado. ${ }^{3}$ De fato, esses dois elementos são claramente pertencentes à tradição da democracia liberal a qual é assumida pelo autor para a elaboração de sua teoria política da justiça. Nesse sentido, poder-se-ia dizer que a valorização das instituições, em vez de o Estado, explicar-se-ia em virtude da ação que elas têm como associação de pessoas e não como representações estatais.

Ainda que seja assim, Rawls desenvolve algumas noções que permitem que se

\footnotetext{
${ }^{3}$ Wolff, por exemplo, argumenta que Rawls não tem uma concepção da geração, da distribuição e da limitação do poder político: ou seja, para ele Rawls não tem uma teoria do Estado (WOLFF, 1977, p. 202). Ainda que esse seja o caso, Kaufman defende, contrariamente, que Rawls tem uma teoria da autoridade política - a qual, de alguma forma, estender-se-ia para os aspectos da administração do Estado: nesses termos, quais princípios devem regular a relação entre os cidadãos de uma sociedade justa e suas instituições? (KAUFMAN, 2014, p. 216). Essa questão, especificamente, diz respeito ao problema da obediência e da autoridade política, na tradição da filosofia política ocidental. Para mais, ver: ROHLING, M. Hart e Rawls. "Fair Play", Obediência ao Direito e Obrigação Política. Lex Humana (Petrópolis), Vol. 5, nº. 2 , p. 121-141, 2013.
}

clarifiquem o seu entendimento do que é um Estado, mesmo que este não seja essencial para a sua teoria. ${ }^{4}$ Já em $T J$, que será o escopo da discussão, dados os princípios de justiça, o Estado aparece como uma "associação constituída de pessoas livres e iguais" e que, ao exercer o seu poder de tal forma a respeitar o espaço individual e particular da busca de suas próprias crenças, valores $e$ interesses, "[...] atua como agente dos cidadãos e satisfaz as exigências da concepção pública de justiça desses mesmos cidadãos" (RAWLS, 2009, §34, p.261).

Como Sarangi afirma, os escritos de Rawls subscrevem uma concepção de Estado democrático liberal sensível ao igualitarismo, ainda que fique claro que o filósofo não seja um teórico que se dedique a pensar o que o Estado é ou deveria ser: antes, Rawls está conceitualizando o tipo de Estado liberal no qual sua teoria opera. Nesse sentido, a noção rawlsiana de Estado é similar àquela de Locke: o Estado é uma sociedade voluntária constituída para a mútua proteção. Está associação voluntária, por sua vez, regula as condições gerais para que os indivíduos possam perseguir seus interesses individuais, e os indivíduos, como deveria ser, são perspectivados como agentes racionais

\footnotetext{
${ }^{4}$ As observações a respeito do Estado no pensamento de Rawls seguem particularmente ROHLING, 2015, p. 393-4.
} 
com interesses e direitos (SARANGI, 1991, p. 195-6). Assim pensado, o Estado é uma associação de pessoas, voluntariamente constituídas, com o monopólio do direito legal, no interior do qual todas as demais associações realizam as suas atividades $e$ que, nesse sentido, deve assegurar interesses fundamentais para todas essas demais associações, tendo em vista a sua abrangência em relação a todas as associações privadas (ROHLING \& VOLPATO DUTRA, 2011, p. 74-5).

Em direção similar, Navarro defende que o Estado, na visão de Rawls, é uma instituição cuja preocupação principal é a de zelar pela equidade nos termos da mantença das condições indispensáveis para que cada qual possa perseguir seus interesses e cumprir com as suas obrigações, tal como as entenda por si mesmo. É curioso que o direito estatal de manter a ordem pública origina-se dessa finalidade de equidade (NAVARRO, 1999, p. 23). Seja como for, Rawls não se restringe apenas à concepção negativa de liberdade, no que se refere às funções do Estado: ele pensa que cada indivíduo necessita de uma esfera garantida de liberdade. É por conta disso que somente um Estado concebido como uma associação civil, vista como um sistema público de regras, com condutas restringidas, pode assegurar tais condições. É através do direito que o Estado pode agir para maximizar as condições para a liberdade individual (ROHLING, 2015, p. 393). Dessa forma, como explica Sarangi, Rawls não parece aceitar uma rígida separação entre o Estado e o indivíduo: os seres humanos são essencialmente criaturas comunais e sociais, de forma que, assim concebidos, os direitos e liberdades individuais não podem ser claramente separados do Estado (SARANGI, 1991, p. 195-6).

Se essa interpretação for válida, há razões para isso, como se observa em $T J$, então, a interpretação de Grueso (GRUESO, 1997, p. 91) é inequivocamente clara: a teoria de Rawls (RAWLS, 2009, §43, p. 342-3) permite identificar qualificadores que precisam o perfil do Estado que subjaz à questão da justiça distributiva - ideias já foram desenvolvidas no artigo Distributive Justice, de 1967. Para Rawls, não apenas em matéria econômica, mas política e administrativamente, o Estado se configura dessa forma: (i) a estrutura social está controlada por uma constituição justa que assegura as diversas liberdades que definem a condição de igual cidadania; (ii) a ordem jurídica é administrada mediante o princípio da legalidade; (iii) existem as liberdades de pensamento e de consciência; (iv) deve haver um processo político justo para eleger governos bem co- 
mo os responsáveis pela criação de leis justas; (v) o governo deve assegurar a todos igualdade de oportunidades no que diz respeito à educação; (vi) o Estado deve assegurar e impor igualdade de oportunidades em empresas comerciais e na livre escolha de ocupação (para este objetivo, deve vigiar o mundo dos negócios e evitar que se estabeleçam barreiras e restrições nos mercados $e$ nas posições desejáveis); e (vii) deve garantir um mínimo social o qual deve ser realizado mediante subsídios familiares e pagamentos especiais em épocas de desemprego, ou, ainda, mediante um imposto negativo sobre a renda.

Partindo da interpretação também do $\S 43$ de TJ, Felipe (FELIPE, 2000, p.154-5) sustenta que Rawls reconhece as seguintes funções sociais como sendo as de um Estado que se pretenda justo. Segundo a autora, o Estado tem: i) a função de aferição de preços a qual assegura a oferta competitiva dos mesmos de tal modo a favorecer a todos; ii) a função de estabilização por meio da qual registra a oferta de empregos e de mãode-obra disponíveis, intercambiando os interesses que são nessas áreas expressos, de empregar e de ser empregado, e o que dela resulta, o pleno emprego para a produção $e$ a oferta de todos os bens essenciais; iii) a função de transferência que estabelece o mínimo de bens a serem socialmente garantidos a todos, sob pena de se cristalizarem desigualdade sociais gritantes entre as pessoas (tendo em vista que as duas funções anteriores não dão conta dessa necessidade, vale dizer, a de suprir as necessidades que colocam em risco a vida e a integridade da pessoa menos favorecida, em termos naturais, acidentais, social familiares; iv) a função distributiva pela qual há a previsão da fixação de tributos sobre heranças e doações, $e$ a cobrança de impostos proporcionais sobre as despesas (como a autora faz ver, para Rawls o imposto sobre consumo é mais adequado do que sobre os salários). A função de distribuição, por meio de suas duas cobranças, é necessária para o Estado justo, porquanto existir a necessidade contínua do custeio de programas destinados a recompensar aqueles que por razões alheias à sua vontade ficam de fora do sistema produtivo e da possibilidade de alcançar os bens primários necessários à preservação da qualidade de vida; e, finalmente, v) a função de intercâmbio, a qual garante o atrelamento de todas as novas propostas de gastos públicos, não apenas à indicação de fonte da qual sairão os recursos, como, ainda, da aprovação por ampla maioria ou por unanimidade, das novas despesas dos governos. 
Dessa forma, o Estado proposto por Rawls, ou pelo menos, com o qual a teoria de Rawls permite interconexão, é um Estado ao mesmo tempo social e liberal: é liberal porque reconhece a prioridade da liberdade, e é social porque é comprometido radicalmente com a equidade das liberdades individuais. Assim, parece correto predicar que é uma versão da concepção liberal-igualitarista do Estado aquela que é pensada por Rawls conforme a justiça como equidade. Segue-se deste modo que o Estado age prioritariamente na distribuição de bens primários e na proteção dos direitos e liberdades fundamentais.

\section{As Políticas Sociais em Educação}

$\mathrm{O}$ que, em geral, entende-se como uma política pública, de caráter social, estendida à educação, isto é, uma política educacional? Políticas educacionais lidam com valores? Mais ainda, têm alguma relação com instituições? Para que estas e outras questões sejam respondidas, convém definir política educacional. Saviani explica que a política educacional é uma modalidade de política social e que esta última está associada a certa maneira de conceber, organizar $e$ operar a administração da coisa pública. Dessa concepção, como indica, deriva o en- tendimento segundo o qual a administração da sociedade é dividida em grandes setores os quais fundamentalmente são, pois, o político, o econômico, o social e o militar (SAVIANI, 2007, p. 204). Mas, essa visão de políticas educacionais como políticas sociais pressupõe um élan social calcado especialmente na racionalidade do materialismo histórico, o que pressupõe uma visão de totalidade. Ainda assim, é uma visão que permite uma compreensão interessante dessa instituição social, muito embora parcialmente.

Partindo de uma matriz teórica semelhante, Bianchetti (2009) partilha do entendimento de Saviani que as políticas educacionais pertencem ao rol das políticas sociais, isto é, aquelas dedicadas à educação, saúde ou habitação, por exemplo, mas, que se referem especificamente às propostas educacionais. Diferentemente de Saviani e Bianchetti, por sua vez, Campos e Rodrigues partem da concepção de políticas públicas como sendo geralmente constituídas e mediadas pelos valores, símbolos e normas de uma determinada sociedade (CAMPOS \& RODRIGUES, 2008, p. 03), de forma que elas mesmas externalizam os propósitos e as finalidades as quais tal sociedade elencou. Uma tal visão possibilita a visão das instituições como externalizando os valores e as características das sociedades onde estas políticas se 
encarnam. Assim vistas, as políticas sociais, como políticas públicas - e nas quais estão inclusas as políticas educacionais - são estratégias promovidas através das instituições políticas tendo por objetivo a construção de um modelo social: trata-se de uma visão de modelo social o qual é composto por planos, projetos e diretrizes na direção da construção de uma determinada forma social.

De fato, trata-se de compreender a políticas sociais como expressão dos valores $e$ dos elementos que constituem uma determinada sociedade mediados pelas instituições políticas. Isso significa dizer que, numa sociedade complexa, em termos de pluralidade de grupos e de instituições para atender os objetivos de uma existência social - como a afirmação de Weber de que o Estado moderno se caracteriza pela burocracia - são estas instituições políticas que dão conta de possibilitar toda a dinâmica social, seja através das reivindicações da sociedade civil organizada, seja das ações do próprio Estado, ou, ainda, das próprias pessoas isoladamente quando da presença na esfera pública.

Recentemente, as políticas sociais têm sido implementadas com o propósito de dirimir as desigualdades que resultam da exploração e da acumulação de riquezas que caracterizam as sociedades contemporâneas. Nesse cenário particular, a educação tem sido vista como uma das áreas mais importantes justamente por entender-se o potencial transformador que a caracteriza. Mas, de que modo o Estado, especialmente aquele que tenha os traços descritos por Rawls, poderia avaliar a justiça destas políticas? Antes ainda, a teoria da justiça do filósofo político pode servir de base para a avaliação de uma política social, especialmente daquelas relacionadas à educação? No que se segue, discutir-se-ão tais elementos.

\section{As Políticas Públicas Sociais em Educação e a Teoria da Justiça como Equidade}

Nesta seção, como indicado, defenderse-á a ideia de que a teoria da justiça como equidade é adequada para a avaliação das políticas públicas sociais em educação. Esta ideia é amparada na tese de que tal teoria propõe uma participação eficaz das instituições e do poder público no combate às iniquidades e desigualdades sociais, de modo a exigir, por parte das instituições, intervenções sociais dos organismos públicos responsáveis em criar e gerir políticas que amenizem as gritantes diferenças sociais presentes no interior da sociedade (OLIVEIRA \& ALVES, 2010, p. 35-6). ${ }^{5}$

\footnotetext{
${ }^{5}$ Estudos prévios sobre a importância da educação em Rawls, e que servem de guia à análise desta seção, foram realizados em: JOHNSTON, J. S. Rawls's Kantian Educational Theory. Educational Theory,
} 
Para Rawls, a justiça das instituições caracterizar-se-ia, num sentido, pela igualdade equitativa de oportunidades. Nesse caso, a educação, como instituição social, é encarregada de assegurar a igualdade de oportunidades por meio da redistribuição dos recursos que compete a ela, pois

[...] o princípio da diferença alocaria recursos para a educação, digamos, para elevar as expectativas de longo prazo dos menos favorecidos. Se tal fim for alcançado dando-se mais atenção aos mais talentosos, é permissível; caso contrário, não. E, ao tomar essa decisão, não se deve aferir o valor da educação apenas no tocante à eficiência econômica $e$ ao bem-estar social. Tão ou mais importante é o papel da educação de capacitar uma pessoa a desfrutar da cultura de sua sociedade e participar de suas atividades, e desse modo de proporcionar a cada indivíduo um sentido seguro de seu próprio valor (RAWLS, $2009, \S 17$, p. 121).

É possível que se interprete que os recursos devam ser comprometidos, em primeiro plano, com os menos favorecidos de tal modo a lhes elevar a expectativa, quanto à realização de seus projetos - e consideremse planos racionais de vida - dentro da sociedade. Se esse é o caso, então, a educação

Vol. 55, n 2, 2005; ROHLING, M. A Educação e a Educação Moral em "Uma Teoria da Justiça" de Rawls. Fundamento - Revista de Pesquisa em Filosofia, $\mathrm{n}^{\circ}$. 4, Jan-Jun, 2012; ROHLING, M. Rawls e a Educação - Apontamentos a partir de Uma Teoria da Justiça. In: MORELLI MATOS, José C. (Org.). Reflexões Filosóficas nas Diversas Áreas do Conhecimento. Florianópolis: Editora da UDESC, 2014; e VALLE, I. R. Justiça na Escola: das Desigualdades Justas à Igualdade sem Adjetivos!, In: VALLE, I. R.; SILVA V. L. G. \& DAROS, M. D. (Orgs.). Educação Escolar e Justiça Social. Florianópolis: Nup, 2010. deve procurar diminuir as desigualdades $e$ que essas não devem ser vistas unilateralmente pelo viés da economia ou do bemestar social, mas, principalmente, pela capacidade de permitir a uma pessoa desfrutar da cultura de sua sociedade, podendo, por conseguinte, participar de suas atividades. Assim sendo, a educação conduziria e reforçaria, no indivíduo, o senso do próprio valor que é, como indicado, um dos principais bens primários, cuja distribuição é orientada pelos princípios de justiça (FREEMAN, 2007, p. 90-2).

O segundo princípio, como se sabe, estabelece que pessoas que tenham talentos semelhantes não sejam, por contingências sociais, fadadas às piores experiências. Ora, o oferecimento de oportunidades educacionais é um modo de serem diminuídas certas disparidades sociais e proporcionar o desfrute de uma quantidade maior de bens primários. Conforme salientado, em si mesma, para Rawls, a distribuição natural de talentos não é justa nem injusta, mas tais atribuições são consequências do modo como as instituições lidam com elas. Desse modo, uma teoria da justiça deve ser tal que dirima essas desigualdades naturalmente arbitrárias, $\mathrm{o}$ que se dá mediante o oferecimento de oportunidades educacionais, inclusive, para ele- 
var as expectativas dos menos dotados naturalmente (ROHLING, 2012, p. 146).

Com efeito, por meio do oferecimento de oportunidades equitativas de formação educacional, a educação permite o acesso aos bens primários e, de modo especial, à autoestima. O valor da educação, assim, é relacionado e medido exclusivamente por permitir ao indivíduo apropriar-se da cultura de sua sociedade e, pode-se dizer, de toda a produção cultural do tipo humano num sentido bem mais amplo. Assim procedendo, inexoravelmente reforçará o valor de si mesmo para os indivíduos. Logo, o valor de uma educação de qualidade não está nas cifras que economicamente se podem galgar, mas justamente na medida em que propicia aos membros de certa sociedade apropriarse de sua produção cultural de tal modo a reforçar, neles mesmos, o sentimento do próprio valor.

Considera-se que essa visão de Rawls é certamente muito positiva e assenta a importância da educação na cultura e na autoestima, e não na formação exclusivamente técnica e preparatória para o trabalho - sem, contudo, excluí-la. Portanto, ao apropriar-se da cultura - florescimento humano, tais como a literatura, as tradições musicais e religiosas, as atividades físicas e artísticas, as produções científicas e técnicas, entre outras
- o indivíduo reforçará o senso do próprio valor, e mais significativamente perseguirá seus fins, quaisquer que sejam eles. ${ }^{6}$

Além disso, como efeito da primeira parte do segundo princípio, obtém-se a implicação de que a sociedade tem o dever de oferecer oportunidades iguais de educação para todos. Disso, como se observou, não se segue que o Estado deva primar por um sistema público de ensino. Um sistema privado de educação é perfeitamente compatível com a concepção da justiça como equidade, desde que proporcione oportunidades iguais de educação para todos os membros da sociedade, que dirimam circunstâncias e condicionamentos de ordem social. Certo é que compreendendo a educação e, sobretudo, a educação formal, como uma instituição que é parte da estrutura básica da sociedade, terse-á o entendimento de que deva preparar o indivíduo para a vida, principalmente, para o exercício de seu papel na sociedade (VALLE, 2010, p. 30). Por essa via, conteúdos que reforcem o valor de si mesmo e que preparem para a cidadania $e$ ao senso de cooperação social e solidariedade, pode-se dizer, estão de acordo com o espírito da proposta da justiça como equidade.

\footnotetext{
${ }^{6}$ Cabe recordar que os princípios de justiça são escolhidos em função da capacidade de proporcionar, em maior quantidade, bens primários para todos de um modo mais equitativo.
} 
No entanto, a educação cumpre outro papel, qual seja, o de desenvolvimento da autonomia individual. Esse aspecto é realizado quando, ao permitir o treinamento $e \mathrm{o}$ aprimoramento dos talentos $e$ aptidões individuais, as pessoas gradualmente vão tendo uma ação refletida pelos princípios de justiça os quais aceitariam como pessoas livres $e$ iguais. Evidentemente, por meio do desenvolvimento do senso de justiça, as pessoas são levadas a aceitar esses princípios e a endossá-los como sendo os que escolheriam numa posição inicial de igualdade (ROHLING, 2012, p. 147). Ora, agir de acordo (e por respeito) com princípios de justiça é, então, agir autonomamente e ter realizado todo o desenvolvimento moral. É verdade que, nesse aspecto, fica clara a influência de Kant e de Rousseau no desenvolvimento moral que Rawls arvora no interior da $T J J^{7}$

Considerando a perversidade das concepções neoliberais de política educacional e, do mesmo modo, levando em conta a educação como um bem público, que deve ser orientada para a cooperação social, é

\footnotetext{
${ }^{7}$ Sobre esse tema, recomendam-se os já referenciados textos: JOHNSTON, James Scott. Rawls's Kantian Educational Theory. Educational Theory, Vol. 55, $\mathrm{n}^{\circ}$ 2, 2005; e ROHLING, Marcos. A Educação e a Educação Moral em "Uma Teoria da Justiça" de Rawls. Fundamento - Revista de Pesquisa em Filosofia, $n^{\circ}$. 4, Jan-Jun, 2012.
}

pertinente afirmar que a teoria de Rawls é adequada para a avaliação das políticas educacionais, já que, conforme o conjunto de proposições da justice as fairness, certo número de políticas sociais, entre elas, aquelas de viés educacional, são fundamentais para que se revertam certas desigualdades não justas: aquelas injustiças não sejam vantajosas para os que estão em posições menos vantajosas devem ser corrigidas por meio do próprio sistema.

Assim posto, as políticas sociais educacionais são fundamentais para a promoção da justiça social, uma vez que permitam proporcionar aos indivíduos o acesso e o usufruto dos bens primários. Com isso, espera-se que tenham os elementos fundamentais para que possam realizar seus planos racionais de vida, quaisquer que sejam eles, bem como mantenham a igualdade equitativa de oportunidades a todos. Dado que as sociedades, especialmente as sociedades democráticas, não sejam homogêneas, econômica, educacional e culturalmente, é preciso que certos reajustes no arranjo social sejam feitos, já que se espera que as políticas sociais sejam capazes da promoção da equidade social.

Os princípios da justiça de Rawls são adequados para a avaliação dessas políticas; procuram promover a equidade social, pre- 
servando o máximo de liberdade igual compatível com uma liberdade extensível para todos, e trabalhando para que as desigualdades sociais, quaisquer que sejam elas, sejam vantajosas para os membros da sociedade, especialmente os menos favorecidos. Assim orientadas, as instituições e as políticas sociais são justas. Quer dizer, então, que a equidade não demanda a eliminação de todas as desigualdades, mas que, das desigualdades, todos sejam beneficiados.

\subsection{A Justiça como Equidade e as Ações}

\section{Afirmativas}

A afirmação da equidade do sistema aqui se deve ter em conta principalmente o segundo princípio de justiça: o princípio da igualdade equitativa de oportunidades e o princípio da diferença -, como forma de atenuação das desigualdades sociais, inclusive, desigualdades sociais no sentido de acesso à educação - educação básica e superior, por exemplo - é uma das direções, através das quais, é possível que se pense a defesa das ações afirmativas na teoria da justiça como equidade, já que Rawls mesmo não se concentrou neste tema. Sobre essa questão, especialmente, dois dos principais intérpretes da obra de Rawls, Freeman e Nagel, apontam algumas breves considerações.
Como Freeman defende, é curioso que o modelo da justiça como equidade, proposto por Rawls em $T J$, rejeita as ações afirmativas como, se pode dizer, políticas de governo. Mas como o autor deixa claro, desse fato não decorre que ela não possa ser usada em políticas públicas, circunstancialmente, para corrigirem graves desigualdades sociais. Isto se explica em virtude de que, conforme Freeman argumenta, Rawls mesmo, em algumas oportunidades, sugeriu que as ações afirmativas podem ser um corretivo às discriminações passadas, que podem ser usadas temporariamente. Contudo, nas condições ideais de uma sociedade justa, ainda assim, as ações afirmativas são incompatíveis com a igualdade equitativa de oportunidades, uma vez que seja conflitante com a ênfase sobre os indivíduos e sobre os direitos individuais (FREEMAN, 2007, p. 90).

Por sua vez, num breve texto chamado John Rawls and Affirmative Action (2003), Nagel defende que a teoria de Rawls é capaz de dar conta da fundamentação das ações afirmativas. Como intérprete, Nagel afirma que o problema das ações afirmativas tem atraído consideravelmente a atenção moral nos últimos 40 anos e, num certo sentido, o clima intelectual no qual Rawls produziu sua obra tem influenciado esse debate, ainda que nada tenha escrito sobre o assunto. As- 
sim, Nagel afirma que a primeira coisa a se dizer é que Rawls se dedicou, durante boa parte de sua vida, a descrever o que ele chamou de teoria ideal, isto é, o que deve constituir verdadeiramente uma sociedade justa e, por ela, indicar quando uma determinada sociedade é injusta. As ações afirmativas, afirma ele, são claramente políticas que têm como meta as consequências injustas de uma história injusta e que, portanto, estão alocadas naquilo que Rawls chama de teoria não ideal (NAGEL, 2003, p. 82).

É verdade que, ao tempo em que Rawls escreveu $T J$, a questão das ações afirmativas não era ainda tão polêmica. Com efeito, Nagel o afirma, Rawls considerou, através de muitas conversas, que, mesmo que a questão das ações afirmativas estivesse omissa em seu opus magno, seria importante a defesa da sua constitucionalidade (NAGEL, 2003, p. 82). Sobre isso, em Justiça como Equidade: uma Reformulação, Rawls explica que:

Esperamos que numa sociedade bem ordenada em condições favoráveis, com liberdades básicas iguais e igualdade equitativa de oportunidades garantidas, gênero e raça não determinem pontos de vista relevantes. Teoria discute apenas duas questões da teoria da aquiescência parcial (ou teoria não-ideal), a desobediência civil e a objeção de consciência a lutar numa guerra injusta. Os graves problemas atuais decorrentes da discriminação e das distinções baseadas em gênero e raça não fazem parte de sua proposta, que é a de formular certos princípios de justiça e confrontá-los apenas com alguns problemas clássicos de justiça política para verificar como seriam resolvidos na teoria ideal.

Trata-se, de fato, de uma omissão em Teoria; mas uma omissão não é, por si só, uma falha, quer na proposta da obra ou em sua concepção política. A existência de uma falha depende de como essa concepção articula os valores políticos necessários para lidar com essas questões. A justiça como equidade, e outras concepções liberais semelhantes a ela, seriam por certo seriamente defeituosas se carecessem dos recursos para articular os valores políticos essenciais para justificar as instituições legais e sociais necessárias para garantir a igualdade das mulheres e das minorias (RAWLS, 2003, p. 93).

De fato, o problema das ações afirmativas, como exemplo de políticas sociais, foi omitido de $T J$ por questões de objetivos. Mas, ainda que esse seja o caso, o que Rawls está dizendo é que a concepção da justiça como equidade mobiliza valores políticos os quais permitem que seja possível estabelecer a sua defesa como forma de assegurar a igualdade das pessoas. Nesse sentido, Nagel aclara que a teoria da justiça como equidade, ao falar da teoria ideal, indica em que sentido uma sociedade pode ser injusta, pois que os princípios de justiça, para que uma sociedade seja justa, requerem três coisas: (i) que seja assegurado, para todos, as liberdades pessoais básicas iguais e status político igual; (ii) que se assegure igualdade equitativa de oportunidades numa competição para as vantagens econômicas e sociais que serão 
inevitavelmente distribuídas desigualmente numa sociedade livre; e (iii) que estas desigualdades de vantagens, na economia, por exemplo, seja parte de um sistema que diminuas as desigualdades socioeconômicas, tanto quanto possível, de forma consistente com a primeira parte do segundo princípio de justiça (NAGEL, 2003, p. 82).

Com isso em mente, Nagel argumenta que as ações afirmativas servem para a inclusão das minorias, que são tradicionalmente oprimidas, nas instituições nas quais elas deveriam estar presentes se os fatores sociais, como o caso do pertencimento a uma etnia ou segmento social, não fossem usados como fator de admissão. Nos termos da concepção de justiça de Rawls, a injustiça que as ações afirmativas devem combater é uma especial forma de fracasso da igualdade equitativa de oportunidades (NAGEL, 2003, p. 82). ${ }^{8}$ Assim pensando, isto quer dizer que o grupo social favorecido não teria condições de competir em igualdade equitativa de

${ }^{8}$ A análise de Nagel privilegia a defesa das ações afirmativas para o caso das etnias, especificamente, da afrodescendente. No entanto, não se enfatiza esse aspecto porque se acredita que, ao se enfatizar as condições de desfavorecimento social, incluem-se não apenas uma parte das parcelas segregadas, mas todas as que, por razões sociais - sejam elas étnicas (indígenas, afrodescendentes, eurodescendentes), de gênero (mulheres, homoafetivos) ou econômicas (pobres, desempregados) - foram oneradas socialmente com a privação do acesso a certos bens primários. oportunidades se não fosse formalmente favorecido por meio dessas ações.

É verdade que uma sociedade justa, num sentido estrito da teoria-ideal, não precisaria de medidas e ações afirmativas. Mas a teoria de Rawls permite iluminar e avaliar as políticas sociais e, entre elas, as políticas educacionais, como é o caso das ações afirmativas educacionais. Nesse sentido, como Nagel compreende, é uma consequência natural do ideal de justiça pensado por Rawls que medidas excepcionais, como as das ações afirmativas, são admitidas se elas servem para retificar e corrigir, no horizonte do plano distintamente não-ideal, injustiças as quais têm afetado grupos de membros da sociedade (NAGEL, 2003, p. 82). Com isso em mente, é absolutamente correto dizer que, ainda que não deva ser uma política de governo, as ações afirmativas são um recurso inequivocamente adequado se, no plano da equidade do sistema, forem organizadas para diminuir as injustiças quanto ao acesso às oportunidades educacionais.

\section{Considerações Finais}

Considerando os traços liberais da política econômica e social brasileira, marcada pelas características da social democracia que Constituição Federal de 1988 imprimiu, é imperativo que se defenda a afirmação dos 
direitos e garantias fundamentais da cidadania. Ainda que seja assim, não se pode dizer que tais direitos e garantias constitucionais sejam efetivados, de forma que as políticas sociais aparecem como meios para a diminuição das disparidades sociais. De fato, elas são formas por meio das quais aqueles cidadãos, inicialmente privados de seus direitos mínimos essenciais, têm acesso à efetivação dos mesmos, mesmo que de forma parcial. Entre tais direitos, a educação aparece como fundamental - e, assim se compreende, sem educação não há como se falar em cidadania. Inobstante, negar o direito à educação é negligenciar os elementos essenciais para uma vida significativa, seja qual for o sentido que cada qual dos cidadãos atribuam a ela. Nesse sentido, poder-se-ia ultimar que o Estado tem o dever de garantir, consoante o que implicam seus princípios, os direitos fundamentais, de tal modo a proporcionar $e$ a possibilitar aos cidadãos as condições necessárias para o exercício de tais direitos, em virtude do que se deve primar pela igualdade de oportunidades quanto ao oferecimento de educação básica para todos. Nessa direção, a obra de Rawls é um poderoso instrumento para se pensar não apenas o direito à educação, mas as políticas públicas relacionadas à educação como um todo.
Dito isso, o que se procurou ofertar foi uma defesa da teoria de Rawls como hábil à avaliação e orientação das políticas públicas sociais, principalmente no que se refere à educação, considerando sobremaneira a sua obra máxima. Em TJ, o ponto crucial é aquele dos princípios de justiça, cuja justificação dá-se mediante a posição original em que a racionalidade das partes opera, tendo em vista a distribuição de uma quantidade maior de bens primários. A justice as fairness se consubstancia nos dois princípios de justiça: o primeiro princípio é o da liberdade igual, ao passo que o segundo é composto de duas partes, a saber: o princípio da igualdade equitativa de oportunidades e o princípio de diferença. A primeira parte do segundo princípio legifera medidas que atenuem, senão façam desaparecer, as desigualdades de ordem social. Assim, esse princípio estabelece que pessoas que tenham talentos semelhantes não sejam, por contingências sociais, fadadas às piores experiências. $\mathrm{O}$ oferecimento de oportunidades educacionais é um modo de se diminuir certas disparidades sociais e proporcionar o desfrute de uma quantidade maior de bens primários. Conforme salientado, em si mesma, a distribuição natural de talentos não é justa ou injusta, mas tais atribuições são consequências do modo como as instituições lidam com elas. 
Desse modo, uma teoria da justiça deverá dirimir essas desigualdades naturalmente arbitrárias, o que se dá mediante o oferecimento de oportunidades educacionais, inclusive, para elevar as expectativas dos menos dotados naturalmente. Esse é o parâmetro de avaliação das políticas sociais educacionais, bem como sua força dinâmica.

Ademais, por meio do oferecimento de oportunidades equitativas de formação educacional, tem-se a educação como um elemento a permitir o acesso aos bens primários, entre os quais a autoestima é o mais importante. Nesse sentido, o valor da educação não é medido pela eficiência ou qualquer bem-estar social que possa proporcionar, mas, exclusivamente por permitir aos indivíduos apropriarem-se da cultura de sua sociedade e de toda a produção cultural humana, num foro amplo. Desse modo, inexoravelmente, reforçará o valor de si mesmos, como pessoas morais, para os indivíduos.

Além disso, como efeito da primeira parte do segundo princípio, tem-se a implicação de que a sociedade tem o dever de oferecer oportunidades iguais de educação para todos. Disso, como se observou, não se segue que o Estado deva primar por um sistema público de ensino. Em $T J$, um sistema de educação privada é perfeitamente compatível com a concepção da justiça como equidade, desde que proporcione oportunidades iguais de educação para todos os membros da sociedade, que dirimam circunstâncias e condicionamentos de ordem social. O papel da educação é, por certo, realizar a autonomia individual ao permitir o desenvolvimento e o treinamento de habilidades e aptidões individuais, possibilitando que as pessoas tenham uma ação refletida pelos princípios de justiça os quais elas aceitariam como pessoas racionais, livres $e$ iguais. Nesse processo, que associado à educação, a pessoa terá realizado sua autonomia quando o senso de justiça resultar formado, pois que ela agiria de acordo com os princípios que ela mesma escolheria numa situação inicial de igualdade - em $T J$, esse aspecto corresponde à estabilidade de uma teoria da justiça, pois ela mesma teria condições de gerar sua manutenção.

\section{Referências}

AZEVEDO, J. A Educação como Política Pública. São Paulo: Autores Associados, 1997. 
BEATTIE, Catherine. Rawls and the Distribution of Education. Canadian Journal of Education, Vol. 7, No. 3, p. 39-50, 1982.

BIANCHETTI, Roberto G. Modelo Neoliberal e Políticas Educacionais. $2^{a}$ ed. São Paulo: Cortez, 1999.

CAMPOS, Rosânia; RODRIGUES, Marílda M. O Princípio Equitativo no Projeto Regional de Educação para a América Latina e Caribe: Princípios Balizadores. UNIVALI, Itajaí, SC: ANPEDSUL 2008.

DANIELS, Norman (Org.). Reading Rawls: Critical Studies on Rawls' A Theory of Justice. Stanford: Stanford University Press, 1989.

FELIPE, Sônia T. Rawls: uma Teoria Ético-Política da Justiça. In: OLIVEIRA, Manfredo A. (Org.) Correntes Principais da Ética Contemporânea. Petrópolis, RJ: Vozes, 2000.

FREEMAN, Samuel. Rawls. New York: Taylor \& Francis e-Library, 2007.

GRUESO, Delfín I. Rawls: Una Hermenéutica Pragmática. Cali: Universidad del Valle, 1997.

HART, L. H. A. Rawls on Liberty and it's Priority. In: DANIELS, N. Reading Rawls: Critical Studies on Rawls' A Theory of Justice. Stanford: Stanford University Press, 1989.

JOHNSTON, James Scott. Rawls's Kantian Educational Theory. Educational Theory, Vol. 55, $\mathrm{n}^{\circ} 2,2005$.

KANT, Immanuel. Pedagogía. Trad. Lorenzo Luzuriaga, José Luis Pascual. $3^{a}$ Ed. Madrid: Akal, 2003.

KAUFMAN, Alexander. Political Authority, Civil Disobedience, Revolution. In: MANDLE, J. \& REIDY, D. A. (Orgs.). A Companion to Rawls. West Sussex: Wiley Blackwell, 2014.

MERQUIOR, J. G. O Liberalismo - Antigo e Moderno. São Paulo: Editora Nova Fronteira, 1990.

NAGEL, Thomas. John Rawls and Affirmative Action. The Journal of Blacks in Higher Education. No. 39, p. 82-4, Spring, 2003.

NAVARRO, Emílio M. Solidariedad Liberal - La Proposta de John Rawls. Granada: Editorial Comares, 1999.

OLIVEIRA, Neiva A. \& ALVES, Marcos A. Justiça e Políticas Sociais na Teoria de John Rawls. Sociedade em Debate (UFPel), Vol. 16, No. 1, p. 25-43, Jan-Jun, 2010.

RAWLS, John. A Theory of Justice. Revised Edition. Cambridge: Harvard University Press, 2000.

. Distributive Justice. In: RAWLS, J. Collected Papers (Org. Samuel Freeman) Cambridge, Mass: Harvard University Press, 1999.

tins Fontes, 2003.

Justiça como Equidade: uma Reformulação. Trad. Cláudia Berliner. São Paulo: Mar-

. O Liberalismo Político. Trad. Dinah de Abreu Azevedo. São Paulo: Ática, 2000.

Uma Teoria da Justiça. Trad. Jussara Simões São Paulo: Martins Fontes, 2009.

ROHLING, Marcos. A Educação e a Educação Moral em "Uma Teoria da Justiça" de Rawls. Fundamento - Revista de Pesquisa em Filosofia, n'. 4, Jan-Jun, 2012.

. Rawls e a Educação - Apontamentos a partir de Uma Teoria da Justiça. In: MORELLI MATOS, José C. (Org.). Reflexões Filosóficas nas Diversas Áreas do Conhecimento. Florianópolis: Editora da UDESC, 2014.

. Hart e Rawls. "Fair Play", Obediência ao Direito e Obrigação Política. Lex Humana (Petrópolis), Vol. 5, nº. 2, p. 121-141, 2013. 
- Rawls e o Direito. A Ordem Jurídica na Teoria da Justiça como Equidade. Revista de Derecho de la Pontificia Universidad Católica de Valparaíso (Valparaíso, Chile), Vol. 44, p. 593-621, 2015.

- Uma Interpretação do Direito à Educação à luz da Teoria de Rawls. Revista Educação (PUCRS. Online). , v.38, p.389 - 403, 2016.

. \& VOLPATO DUTRA, Delamar J. O Direito em "Uma Teoria da Justiça” de Rawls. Dissertatio (UFPel), v. 34, p. 63-89, 2011.

ROSAS, João C.; THALER, Mathias; \& GONZÁLEZ, Iñigo. Filosofia Política. In: GALVÃO, P. (Org.) Filosofia: Uma Introdução por Disciplinas. Lisboa: Edições 70, 2012.

SARANGI, Prakash. Notion of 'State' in John Rawls' Theory of Justice. The Indian Journal of Polical Science. Vol. 52, No 2, April-June, p. 195-207, 1991.

SAVIANI, Demerval. Da Nova LDB ao Fundeb: por uma outra política educacional. Campinas: Autores Associados, 2007.

VALLE, Ione R. Justiça na Escola: das Desigualdades Justas à Igualdade sem Adjetivos!' In: VALLE, Ione R.; SILVA Vera Lúcia G. da \& DAROS, Maria das Dores (Orgs.). Educação Escolar e Justiça Social. Florianópolis: Nup, 2010.

WOLFF, Robert P. Understanding Rawls. New Jersey: Princeton, 1977.

Recebido em: 22/12/2016 Aprovado em: 18/05/2017 